\title{
Apical Sealing Efficacy of the Bioceramic Cements Bio Root and MTA Fillapex: An ex vivo Study
}

\author{
Eficacia del Sellado Apical de los Cementos Biocerámicos \\ Bio Root y MTA Fillapex: Un Estudio ex vivo
}

\author{
Daniel Aracena'; Luis Bustos²; Angella Aracena ${ }^{3}$; Paula Alvarez ${ }^{4}$ \& Scarlette Hernández-Vigueras ${ }^{5}$
}

\begin{abstract}
ARACENA, D.; BUSTOS, L.; ARACENA, A.; ALVAREZ, P. \& HERNÁNDEZ-VIGUERAS, S. Apical sealing efficacy of the bioceramic cements Bio Root and MTA Fillapex: an ex vivo study. Int. J. Odontostomat., 15(2):473-478, 2021.

ABSTRACT: The aim of this ex vivo study was to compare the ability of the apical sealing bioceramic cements BioRoot ${ }^{\text {TM }}$ RCS (Septodont) and MTA-Fillapex (Angelus). One hundred and eighty-four vestibular canals were selected from ninety-two recently extracted maxillary molars. Canals were instrumented with the mechanized system ProTaper Next and obturated using the single cone technique. The sample was randomly divided into two groups (92): Group 1 was obturated with BioRoot TM RCS, and Group 2 with MTA-Fillapex. Samples were processed for the leakage test by dye penetration and later cut longitudinally. The data obtained were tabulated and analyzed using Stata 15.0. The degree of leakage from BioRoot ${ }^{\mathrm{TM}} \mathrm{RCS}$ was $0.03 \mathrm{~mm}$, and MTA-Fillapex was $0.31 \mathrm{~mm} \mathrm{p}(0.00)$. BioRoot ${ }^{\mathrm{TM}}$ bioceramic presented an adequate apical sealing, while MTA-Fillapex showed an accentuated leakage.
\end{abstract}

KEY WORDS: Root canal filling materials, root canal obturation, filtration, bioceramic.

\section{INTRODUCTION}

Root obturation contemplates the three dimensional filling of the root canal system with materials that present satisfactory physicochemical and biological properties (Rekab \& Rushdi Ayubi, 2010).

The apical third is the most complex and critical area of the root canal systems, not only because of its instrumentation, but also because of its obturation. This is because infection or reinfection can occur due to the persistence of bacteria in the dentinal tubules (Wang et al., 2018).

Ideally, to achieve a biological seal, the filling material should adequately complete the root canal, avoid fluid filtration in the root space, favor resolution of periapical pathologies and stimulate the cement deposit (Rekab \& Rushdi Ayubi; De Vasconcelos et al., 2011; Ozbay et al., 2014; Reszka et al., 2016).
Grossman described the characteristics that root canal filling materials must present: good adhesion to the dentinal walls, dimensional stability, insoluble in tissue fluids, biocompatibility, antibacterial properties, radiopacity, and easy handling (Grossman, 1982).

These materials should stimulate, and not interfere with, the healing process, assuring the persistence of the cleaning obtained by the chemicalmechanical preparation, permitting apical healing. In this manner, we avoid the appearance, or recurrence, of periradicular pathology (Rekab \& Rushdi Ayubi; Torabinejad et al., 2018).

With advances in modern dentistry, cleaning and shaping of root canals can be done efficiently. These advances have resulted in successful endodontic

${ }^{1}$ Dental School, Faculty of Sciences, Universidad Mayor, Temuco, Chile.

${ }^{2}$ Department of Public Health, CIGES, Faculty of Medicine, Universidad de La Frontera, Temuco, Chile.

${ }^{3}$ Undergraduate Research Group in Odontology, Faculty of Health Sciences, Universidad Autónoma de Chile, Chile.

${ }^{4}$ Postgraduate Endodontic, Universidad Mayor, Temuco, Chile.

${ }^{5}$ Faculty of Medicine, Odontostomatology Institute, Universidad Austral de Chile, Valdivia, Chile.

Received: 2020-09-03 Accepted: 2020-12-22 
therapy of almost $90 \%$ (Ozbay et al.; Torabinejad et al). Root canal shaping with rotary instruments uses gutta-percha and cement to seal the canal and the irregularities of the wall by penetrating into the dentinal tubules. This is performed to obtain a hermetic and homogeneous filling, avoiding bacterial recolonization of the canal radicular (Parirokh \& Torabinejad, 2010).

Furthermore, the apical, lateral and coronal sealing avoid the recontamination and assure clinical success over time. (Rekab \& Rushdi Ayubi).

Bioceramic cements are biocompatible materials with improved sealing capacity that have antibacterial and antimicrobial activity for use in medicine and dentistry (Calikten et al., 2016). They can function as human tissues or be reabsorbed to stimulate regeneration of natural tissues. Bioceramics include alumina and zirconia, bioactive glass, glass ceramics, calcium silicates, hydroxyapatite and resorbable calcium phosphates among others (Candeiro et al., 2016).

These cements show excellent biocompatibility due to their similarity to biological hydroxyapatite, and their intrinsic osteoinductive capacity. This is due to their capacity to absorb osteoinductive substances if there is a proximal bone healing process. The ability of biocements to achieve an air tight seal, form a chemical bond with the tooth structure and good radiopacity are differentiating factors from other cement sealers (Jain \& Ranjan, 2015; Candeiro et al.; Raghavendra et al., 2017).

These cements work as resorbable regenerative scaffolds that eventually dissolves as the body reconstructs the tissue (Jain \& Ranjan; Raghavendra et al.).

In relation to the methods used to measure cement sealing capacity, and apical leakage, radioisotopic dyes, bacteria and their metabolites have been used in the last decades. However, the most common method is dye penetration given that it indicates the space that remains between the canal wall and obturation material (Prati \& Gandolfi, 2015).

The aim of this ex vivo study was to compare the apical sealing efficiency between the biocements BioRoot TM RCS (Septodont and MTA-Fillapex (Angelus) when root canals are obturated with the single cone technique.

\section{MATERIAL AND METHOD}

The Ethics Committee of the University Mayor, Temuco, Chile (F:0103), approved this ex vivo study.

Ninety-two maxillary first molars were selected with 184 vestibular canals from patients spontaneously recurring to emergency dental services at the Regional Hospital of Temuco Dental Center, Chile. Teeth were extracted due to caries or periodontal disease. Inclusion criteria were: mature apexes, canalicular curvatures $\leq 34^{\circ}$, canals with independent foramina, no calcification and no reabsorptions.

All samples were instrumented with the mechanized system ProTaper Next, (DentsplyMaillefer $\AA$, Ballaigues, Switzerland) X1, X2 and X3 and later obturated with gutta-percha cones $X 3$ of the same system, resulting in 184 obturated canals. Samples were randomly selected and divided into two groups. Group 1 included 92 canals obturated by single cone tecnique and Bioceramic cement BioRoot TM RCS (Septodont, Saint-Maur-des-Fossés, France). Group 2 included 92 canals obturated by single cone technique and the Bioceramic cement MTA Fillapex (Angelus, Londrina, Brazil).

Molars teeth were subjected to the following protocol once extracted: they were submerged into a sodium hypochlorite solution of $5.25 \%$ for 20 minutes to ensure the disinfection and elimination of organic residues. After rinsing with water, any caries and restorations were removed from samples, and then maintained in a $0.9 \%$ saline till use. The access opening was prepared with a high speed round diamond bur $801 \mathrm{~L}$ (Jota ${ }^{\circledR}$, Rüthi, Switzerland) and subsequently finished by removing all of the chamber roof with an Endo-Z Bur (Dentsply-Maillefer®, Ballaigues, Switzerland), both cooled with air-water spray.

Subsequently, each sample was placed on a plaster block to continue with the instrumentation. Root canals were shaped, using the protocol defined by the manufacturer. The canals were instrumented with K10 and K-15 file, Dentsply-Maillefer ${ }^{\circledR}$ (Ballaigues, Switzerland) using the balanced forces technique, and then a sweeping motion with $\mathrm{X} 1, \mathrm{X} 2$ and $\mathrm{X} 3$ Protaper Next files until reaching the previously determined work length.

Canals were permeabilized with a $\mathrm{K} 10$ file 
between each file used and irrigated with $5 \mathrm{cc}$ of $5 \%$ sodium hypochlorite solution.

The smear layer was removed by a rinse with $3 \mathrm{ml}$ of $17 \%$ ethylendiaminetetraacetic acid (EDTA) for 60 seconds followed by a final rinse with $3 \mathrm{ml}$ of 5.25 NAOCL.

An X-Smart Plus motor (Dentsply/Maillefer $§$, Ballaigues, Switzerland) was used with the software indicated for Protaper Next system files.

After root canal obturations were done, crown accesses were filled with Ketac Molar ® Easymix (3M, Deutschland, Germany) and root surfaces except for the apical $2 \mathrm{~mm}$ were coated with two layer of nail varnish, in order to avoid leakage of the dye.

Then, samples from each group were placed in a glass receptacle previously labeled with methylene blue $0.2 \%$. These receptacles were subjected to a temperature of $37^{\circ} \mathrm{C}$ in a thermoregulated bath (Water Batch YCW-04M.Lab Tec) at $100 \%$ humidity for $24 \mathrm{~h}$.

After, longitudinal wear were made on the roots, from vestibular wall until arriving at the canal. Worn roots were photographed with a Nikon Coolpix $®$ P510 digital camera (Melville, USA) with an optical zoom of $42 x$ and $2 \mathrm{~s}$ timer.

The camera was positioned on a standard tripod (Digiti Life) at $11 \mathrm{~mm}$ from the sample to be photographed. Roots were placed on a millimeter ruler for reference. Photographs were analyzed in Adobe Illustrator (CC2018 22.0.1.253) on a real scale. Measurements were in $\mathrm{mm}$, from the apical end gutta-percha cone to the region with staining.

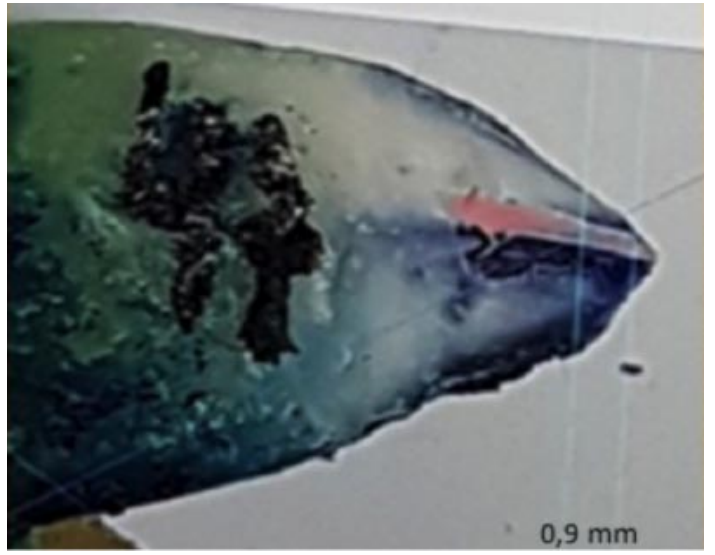

Fig. 1. Apical leakage stained with methylene blue
Table II. Degree of apical leakage according to bioceramic cement.

\begin{tabular}{lllll}
\hline & & Bio-root & Fillapex & Total \\
\hline 0 & $\mathrm{n} \%$ & $89(96.7 \%)$ & $68(73.9 \%)$ & $157(85.3)$ \\
& $\mathrm{x} \pm \mathrm{s}$ & 0 & 0 & \\
& $\min \mathrm{y} \max$ & 0 & 0 & \\
Light & $\mathrm{n}(\%)$ & $2(2.2 \%)$ & $13(14.1 \%)$ & $15(8.2)$ \\
& $\mathrm{x} \pm \mathrm{s}$ & $0.5 \pm 0.57$ & $0,7 \pm 0.26$ & \\
& $\min -\max$ & $0.1-0.9$ & $0.1-1$ & \\
Regular & $\mathrm{n}(\%)$ & $1(1.1 \%)$ & $8(8.7 \%)$ & $9(4.9)$ \\
& $\mathrm{x} \pm \mathrm{s}$ & $1.8 \pm$ & $1,5 \pm 0,35$ & \\
& $\min -\max$ & $1.8-1.8$ & $1.1-1.9$ & \\
Extensive & $\mathrm{n}(\%)$ & 0 & $3(3.3 \%)$ & $3(1.6)$ \\
& $\mathrm{x} \pm \mathrm{s}$ & - & $2.1 \pm 0.06$ & \\
\multirow{5}{*}{ Total: } & $\min -\max$ & - & $2.1-2.2$ & \\
& & 92 & 92 & 184 \\
& & $0.03 \pm 0.21$ & $0.3 \pm 0.60$ & \\
& & $0-1.8$ & $0-2.2$ & \\
\hline
\end{tabular}

Leakage levels were classified in the following manner: Null apical leakage; staining area measures 0 $\mathrm{mm}$ / Light leakage; stained area measures 0.1 to $1 \mathrm{~mm}$. / Regular leakage; stained area measures between 1.1 and $2 \mathrm{~mm}$. / Extensive leakage; stained area measures between 2.1 and $3 \mathrm{~mm}$. / Severe leakage; stained area is greater than or equal to $3.1 \mathrm{~mm}$.

All data were entered into an Excel spreadsheet and analyzed in the statistical software Stata ${ }^{\circledR}$ v16.0. For comparison of averages, the unequal variances ttest was used as well as Fisher's exact test for the percentages. Level of significance was $5 \%$.

\section{RESULTS}

In a sample of 184 vestibular canals, half treated with Bio-Root sealer and the other half with Fillapex, statistically significant differences were found in the leakage averages, being higher in Fillapex (Table I) (Fig. 1).

Upon comparing apical leakage between the sealers, significant differences were observed on different levels. In the canals obturated with Bio-Root, $96.7 \%$ were without leakage, compared with $73.9 \%$ for Fillapex (Table II).

Table I. Measurement of apical leakage $(\mathrm{mm})$ in vestibular canals with two bioceramic cements.

\begin{tabular}{lccc}
\hline Cement & $\mathrm{n}$ & Mean $\pm \mathrm{s}$ & $\mathrm{p}$ \\
\hline Bio-Root & 92 & $0.03 \pm 0.21$ & 0.0001 \\
Fillapex & 92 & $0.31 \pm 0.60$ & \\
\hline
\end{tabular}

Unequal variances t-test.

$X=$ average,$s=$ standard deviation, Fisher's exact test $(p<0.001)$ 


\section{DISCUSSION}

A sealer's general purpose is to seal irregularities between the root canal wall and the gutta-percha (Reszka et al.). However, large areas of sealing cement dissolve more easily than thin areas, which translates into future spaces or pores that promote failure of the endodontic treatment (Rekab \& Rushdi Ayubi; Parirokh et al., 2018).

One study evaluated the sealing capacity of three canal sealers through the leakage test by dye penetration: AH Plus, Acroseal and Sealapex, as well as two experimental sealers (MBP and MTA Obtura). The study concluded that all sealers showed apical leakage (De Vasconcelos et al.).

In recent years, materials based on calcium silicate have improved root canal obturation quality. Studies on this material show bioactivity, biocompatibility and an excellent sealing capacity in the presence of humidity in vivo (Rekab \& Rushdi Ayubi).

Dental cells bind with these biomaterials, closing porosities that exist in the interface. This indicates tropism towards these silicate cement allowing reparation through cell proliferation and migration (AL-Haddad \& Che Ab Aziz, 2016; LoisonRobert et al., 2018).

At the same time, other researchers sustain that these cements, upon forming a layer of hydroxyapatite, fill pores and superficial defects on the interface through a chemical bond, which is responsible for their hermetic sealing (Torabinejad et al.). This sealing capacity varies according to the composition of the bioceramic used. As it was confirmed in our study, where we compared the cements Bio-Root and Fillapex, the former presented high levels of airtightness, $0.03 \mathrm{~mm}$ of apical leakage, compared to $0.31 \mathrm{~mm}$ of leakage presented by the latter $p(0.00)$. A possible explanation for these differences could be that the Bio Root cement is composed of pure calcium silicate, while Fillapex contains resin, which does not reach the same level of sealing with the dentin (Viapiana et al., 2016).

Similarly, another work regarding bioceramics reiterates that the sealing capacity of Bio-Root RCS is obtained by its prolonged ability to liberate calcium ions, promoting sealing through mineralization and hydroxyapatite formation in the root canal interface.
Meanwhile, Fillapex does not have the capacity to liberate calcium ions and has a lower hydroxyapatite deposit, therefore exhibiting lesser sealing efficiency (Siboni et al., 2017).

Cleaning the dentinal surface by removing the smear layer is an essential step in the process of successful root canal treatment (Zmener et al., 2005). It is also important the elimination of smear layer from the canal with EDTA $10 \%$ for 60 seconds. This is because it could contain bacteria that can proliferate into the dentin tubules, allowing deeper penetration into the dental tissue. In turn, the sealing ability is decreased when the cement bonding with the tooth (Wu \& Wesselink, 2001). Therefore, the penetration of the sealer into dentinal tubules is desirable because it produces a blockage that impedes the passage of bacteria and toxins (Torabinejad et al.).

A study evaluated the dentinal tubule penetration ability for the cements AH Plus, MTA Fillapex and Gutaflow, in roots canals obturated using cold lateral compaction in either the presence or absence of smear layer. The authors concluded that the depth of sealer penetration was statistically significant in the groups where smear layer was removed compared with those without its removal p $<0.05$ (Sonu et al., 2016).

In contrast with these conclusions, other authors affirm that apical leakage is lesser when smear layer is present. They speculate that it could act as a bonding agent, given that its wet surface could cause a positive effect on the adaptation of bioceramic sealers which are hydrophilic. (Rekab \& Rushdi Ayubi). In our study, we did remove the smear layer with $17 \%$ EDTA for 1 minute, obtaining a high degree of apical airtightness. We observed this result only when using the cement Bio Root what did not contain resin, but we did not study the variation of apical leakage, without removing the smear layer.

Different methods have been evaluated introducing endodontic sealers into root canals, and covering dental walls in a uniform and complete manner. In this regard, it is asserted that bioceramic cements penetrate more root canal segments with single cone technique than resinous cements, which is probably related to their high fluidity and smaller particle size (Wang et al.). 
Smaller sized particles increase surface contact with the liquid and lead to greater early strength as well as ease of handling (Torabinejad et al). A study about sealers penetration in dentinal tubules with $\mathrm{AH}$ Plus, iRoot SP, MTA Fillapex and GuttaFlow Bioseal and single cone root canal obturation, showed that iRoot SP had significantly greater penetration than the other groups (Akcay et al., 2016). These results are similar to our study, in which we achieved a better seal with the pure bioceramic cement Bio-Root $(96.7 \%)$ than the resinous cement Fillapex (73.9\%).

Regarding how to put sealer into the canals, we affirm that applying the cement sealer with a paste carrier obtains better depth and percentage of penetration, given that it pushes the cement in a centrifugal manner into the root canal walls (Kumar et al., 2017). In our study, bioceramics Bio-Root and Fillapex were introduced into canals by the paste carrier Paste Injec, (MicroMega $\circledast$, Besançon, France), achieving a complete and homogeneous covering of the root canal walls. Several methods have been recommended to evaluate apical leakage such as linear dye leakage, electrochemical method, radioisotope labeling, bacterial leakage and fluid filtration (Kardon et al., 2003; De Vasconcelos et al.).

Methylene blue dye was used in this study because it easily allows quantitative measures of the extent of dye penetration by linear measurement techniques, and its molecular size is similar to bacteria (Kersten \& Moorer, 1989).

However dye penetration studies have the limitation of measuring the degree of leakage only in one plane, which makes impossible to measure the total quantity of leakage (Ozbay et al.). On the contrary, another study declares that methylene blue is decoloured when it is in contact with alkaline obturation materials, causing hydrolysis. This can lead to unreliable conclusions in leakage tests (Wu et al., 1998).

More studies are required to clarify the results pertaining to these endodontic sealers. However, among the limitations of this study, we can conclude that BioRoot cement can help to improve root canal sealing, unlike resinous bioceramics, such as Fillapex, that have higher degree of leakage.

ARACENA, D.; BUSTOS, L.; ARACENA, A.; ALVAREZ, P. \& HERNÁNDEZ-VIGUERAS, S. Eficacia del sellado apical de los cementos biocerámicos Bio Root y MTA Fillapex: un estudio ex vivo. Int. J. Odontostomat., 15(2):473-478, 2021.
RESUMEN: El objetivo de este studio ex vivo fue comparar la capacidad de sellado apical de dos cementos biocerámicos, el BioRoot ${ }^{\mathrm{TM}}$ RCS (Septodont) y MTA-Fillapex (Angelus). 184 conductos vestibulares fueron seleccionados de 92 molares maxilares recientemente extraídos. Los conductos fueron instrumentados con el sistema de instrumentación mecanizado Protaper Next y obturados usando la técnica de cono único. Las muestras fueron divididas aleatoriamente en dos grupos (N 92): Grupo 1 fue obturado con BioRoot ${ }^{\mathrm{TM}} \mathrm{RCS}$, y el grupo 2 con MTA-Fillapex. Las muestras fueron procesadas para el test de filtración por penetración de tinción, y luego cortadas de manera longitudinal. Los datos obtenidos fueron tabulados y analizados usando Stata 15.0. El grado de penetración de BioRoot ${ }^{\mathrm{TM}}$ RCS fue de 0,03 mm, y de MTA Fillapex fue de $0,31 \mathrm{~mm}$ (P 0.00). BioRoot ${ }^{\mathrm{TM}}$ RCSpresent un sellado apical adecuado, mientras que MTA Fillapex mostró una filtración mayor.

PALABRAS CLAVE: Material de obturación radicular, obturación radicular, filtración, biocerámicos.

\section{REFERENCES}

Akcay, M.; Arslan, H.; Durmus, N.; Mese, M. \& Capar, I. D. Dentinal tubule penetration of AH Plus, iRoot SP, MTA fillapex, and guttaflow bioseal root canal sealers after different final irrigation procedures: A confocal microscopic study. Laser Surg. Med., 48:70-6, 2016.

AL-Haddad, A. \& Che Ab Aziz, Z. Bioceramic-based root canal sealers: a review. Int. J. Biomater., 2016:9753210, 2016.

Calikten, B.; Uzuntas, C. F.; Orhan, A. I.; Orhan, K.; Tufenkci, P.; Kursun, $S$ \& Demiralp, K. Ö. Evaluation of root canal sealer filling quality using a single-cone technique in oval shaped canals: An In vitro Micro-CT study. Scanning, 38:133-40, 2016.

Candeiro, G. T.; Moura-Netto, C.; D'Almeida-Couto, R. S.; AzambujaJúnior, N.; Marques, M. M. \& Cai, S. Cytotoxicity, genotoxicity and antibacterial effectiveness of a bioceramic endodontic sealer. Int. Endod. J., 49:858-64, 2016.

De Vasconcelos, B. C.; Bernardes, R. A.; Duarte, M. A.; Bramante, C. M. \& De Moraes, I. G. Apical sealing of root canal fillings performed with five different endodontic sealers: analysis by fluid filtration. J. Appl. Oral Sci., 19:324-8, 2011.

Grossman, L. Endodontic Practice. 10th ed. Philadelphia, Lea \& Febiger; 1982.

Jain, P \& Ranjan, M. The rise of bioceramics in endodontics: A review. Int. J. Pharm. Biol. Sci., 6:416-22, 2015.

Kardon, B. P.; Kuttler, S.; Hardigan, P. \& Dorn, S. O. An in vitro evaluation of the sealing abilityof a new root canal obturation system. J. Endod., 29:658-61, 2003.

Kersten, H. W. \& Moorer, W. R. Particles and molecules in endodontic leakage. Int. Endod. J., 22:118-24, 1989.

Kumar, A.; Farista, S.; Dash, A.; Bendre, A. \& Farista, S. Comparison of three different sealer placement techniques:An in vitro confocal laser microscopic study. Contemp. Clin. Dent., 8:310-4, 2017.

Loison-Robert, L. S.; Tassin, M.; Bontre, E.; Berbar, T.; Isaac, J.; Berdal, A.; Simon, S. \& Fournier, B. P. J. In vitro effects of two silicate-based materials, Biodentine and BioRoot RCS, on dental pulp stem cells in models of reactionary and reparative dentinogenesis. PLoS One, 13:e0190014, 2018. 
Ozbay, G.; Kitiki, B.; Peker, S. \& Kargul, B. Apical sealing ability of a novel material: analysis by fluid filtration technique. Acta Stomatol. Croat., 48:132-9, 2014

Parirokh, M. \& Torabinejad, M. Mineral Trioxide Aggregate: A comprehensive literature Review-Part III: Clinical applications, Drawbacks, and Mechanism of action. J. Endod., 36:400-13, 2010.

Parirokh, M.; Torabinejad, M. \& Dummer, P. M. H. Mineral trioxide aggregate and other bioactive endodontic cements: an updated overview - part II: other clinical applications and complications. Int. Endod. J., 51:284-317, 2018.

Prati, C. \& Gandolfi, M. G. Calcium silicate bioactive cements: Biological perspectives and clinical applications. Dent. Mater., 31(4):351-370, 2015.

Raghavendra, S. S.; Jadhav, G. R.; Gathani, K. M. \& Kotadia, P. Bioceramics in endodontics - A Review. J. Istanbul Univ. Fac. Dent., 51:128-37, 2017.

Rekab, M. S. \& Rushdi Ayubi, H. Evaluation of the apical sealability of MTA and Portland Cement as root canal filling cements: An in vitro study. J. Dent. Tehran, 7:205-13, 2010.

Reszka, P.; Nowicka, A.; Lipski, M.; Dura, W.; Drozdzik, A. \& Woz'niak, K. A comparative chemical study of calcium silicatecontaining and epoxy resin-based root canal sealers. BioMed Res. Int., 9808432, 2016.

Siboni, F.; Taddei, P.; Zamparini, F.; Prati, C \& Gandolfi, M. G. Properties of BioRoot RCS, a tricalcium silicate endodontic sealer modified with povidone and polycarboxylate. Int. Endod. J., 50:e120-36, 2017.

Sonu, K. R.; Girish, T. N.; Ponnappa, K. C.; Kishan, K. V. \& Thameem, P. K. Comparative evaluation of dentinal preparation of three different endodontic sealer. Saudi Endod. J., 6:16-20, 2016.

Torabinejad, M.; Parirokh, M. \& Dummer, P. M. H. Mineral trioxide aggregate and other bioactive endodontic cements: an updated overview. - part II: other clinical applications and complications. Int. Endod. J., 51:284-317, 2018.

Viapiana, R.; Moinzadeh, A. T.; Camilleri, L.; Wesselink, P. R.; Tanomaru Filho, M. \& Camilleri, J. Porosity and sealing ability of root fillings with gutta-percha and BioRoot ${ }^{\mathrm{TM}} \mathrm{RCS}$ or AH Plus sealers. Evaluation by three ex vivo methods. Int. Endod. J., 49:774-82, 2016.

Wang, Y.; Liu, S. \& Dong, Y. In vitro study of dentinal tubule penetration and filling quality of bioceramic sealer. Plos One, 13:e0192248, 2018.

Wu, M. K. \& Wesselink, P. R. A primary observation on the preparation and obturation of oval canal. Int. Endod, J., 34:137-41, 2001.

Wu, M. K.; Kontakiotis, E. \& Wesselink, P. R. Decoloration of $1 \%$ methylene blue solution in contact with dental filling materials. J. Dent., 26:585-9, 1998.

Zmener, O.; Pameijer, C. H. \& Banegas, G. Effectiveness in cleaning oval-shaped root Canals using anatomic endodontic technology, profile and manual instrumentation: A scanning electron microscopic study. Int. Endod. J., 38:356-63, 2005.
Dirección para correspondencia:

Scarlette Hernández-Vigueras

Instituto de Odontoestomatología

Rudloff 1640

Valdivia

CHILE

E-mail: shernandez@uach.cl 